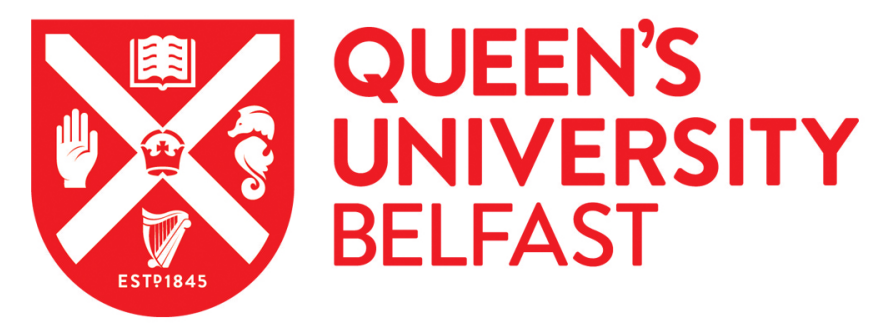

\title{
Surface-enhanced Raman spectroscopy of novel psychoactive substances using polymer-stabilized Ag nanoparticle aggregates
}

Lee, W. W. Y., Silverson, V. A. D., Jones, L. E., Ho, Y. C., Fletcher, N. C., McNaul, M., Peters, K. L., Speers, S. J., \& Bell, S. E. J. (2016). Surface-enhanced Raman spectroscopy of novel psychoactive substances using polymer-stabilized Ag nanoparticle aggregates. Chemical Communications, 52, 493-496.

https://doi.org/10.1039/c5cc06745f

Published in:

Chemical Communications

Document Version:

Peer reviewed version

Queen's University Belfast - Research Portal:

Link to publication record in Queen's University Belfast Research Portal

Publisher rights

(C) 2015 The Royal Society of Chemistry

\section{General rights}

Copyright for the publications made accessible via the Queen's University Belfast Research Portal is retained by the author(s) and / or other copyright owners and it is a condition of accessing these publications that users recognise and abide by the legal requirements associated with these rights.

Take down policy

The Research Portal is Queen's institutional repository that provides access to Queen's research output. Every effort has been made to ensure that content in the Research Portal does not infringe any person's rights, or applicable UK laws. If you discover content in the Research Portal that you believe breaches copyright or violates any law, please contact openaccess@qub.ac.uk. 


\section{Journal Name}

\section{COMMUNICATION}

\section{Surface-enhanced Raman spectroscopy of novel psychoactive substances using polymer-stabilized Ag nanoparticle aggregates}

Received 00th January 20xx Accepted 00th January 20xx

DOI: $10.1039 / \times 0 \times x 00000 x$

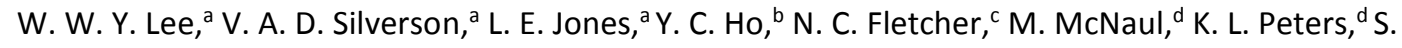
J. Speers ${ }^{\mathrm{e}}$ and S. E. J. Bell ${ }^{\mathrm{*}}$

www.rsc.org/

A set of seized "legal high" samples and pure novel psychoactive substances have been examined by surfaceenhanced Raman spectroscopy using polymer-stabilized $\mathrm{Ag}$ nanoparticle (Poly-SERS) films. The films both quenched fluorescence in bulk samples and allowed identification of $\mu \mathrm{g}$ quantities of drugs collected with wet swabs from contaminated surfaces.

The upsurge in the availability and use of novel psychoactive substances (NPS) such as cathinones has set new challenges for law enforcement and public health protection agencies. In particular the unprecedentedly high rate at which novel variants appear sets challenges for the justice system, both in formulating legislation which covers novel variants and in identifying the materials for the purposes of criminal prosecution without recourse to standard samples for comparison. The fact that particular novel variants may pose significant health risks also means there is a real need to be able to identify compounds as rapidly as possible, preferably in the field. Similarly, the ability to identify trace samples of drugs as well as bulk powders is desirable since it can assist in investigations by allowing residues to be detected on items possibly involved in drug-related activity, such as electronic balances, packaging etc. These requirements are not met by traditional methods for the identification of drugs of abuse such as GC-MS and LC-MS which depend on large, laboratory-based instrument and were developed to meet the needs of a much more stable forensic environment, where most cases involved

aInnovative Molecular Materials Group, School of Chemistry and Chemical Engineering, Queen's University Belfast, UK, BT9 5AG. Tel: +44 2890974470 s.bell@qub.ac.uk.

${ }^{b}$ Forensic Science Centre, New Taipei City Police Department, New Taipei City, 22005, R.O.C. (Taiwan).

'Department of Chemistry, Lancaster University, Lancaster, UK, LA1 4YB.

${ }^{d}$ Forensic Science Northern Ireland (FSNI), Carrickfergus, UK, BT38 8PL.

eSchool of Veterinary and Life Sciences, Murdoch University, Western Austrailia, WA 6150.

Electronic Supplementary Information (ESI) available: [detailed experimental procedures and analytical data]. See DOI: 10.1039/x0xx00000x one of a finite set of well-known substances, such as cocaine or cannabis. At the other extreme there are many colorimetric tests which can be used for presumptive indicators of drugs, ${ }^{1,2}$ and are excellent for field use, however, these lack the specificity and sensitivity of GC-MS and LC-MS. For this reason, there is a need for new approaches which have high sensitivity and specificity but are rapid, easy to operate and preferably portable for on-site use.

Raman spectroscopy is an obvious choice and Raman methods are starting to become established as potentially useful in many different areas of forensic science, including drugs, $^{3-6}$ paints, ${ }^{7-9}$ explosives, ${ }^{10-12}$ inks, ${ }^{13-15}$ lipsticks ${ }^{16-18}$ etc. Moreover, portable hand held Raman systems are now being used by first responders at white powder incidents where the ability to identify materials with no sample preparation is extremely useful, for example in distinguishing between anthrax ${ }^{19}$ and corn starch ${ }^{20}$. However, most of the forensic applications of Raman spectroscopy have used normal spontaneous Raman scattering measurements, which has low sensitivity and so is confined to identifying only the major constituents within a sample. Moreover, with illicit drug samples interference from fluorescence due either to deliberately added dyes and pigments is a potential problem, as is fluorescence from adventitious impurities which may be present in samples prepared using low purity reagents and excipients.

Surface-enhanced Raman spectroscopy (SERS) has the potential to overcome these limitations by providing both high sensitivity ${ }^{21}$ and fluorescence quenching. ${ }^{22-24}$ There has been a considerable amount of research on SERS for the trace detection of samples of forensic interest.6,11,15 Compact instruments suitable for reading SERS signals are now available, the main limitation is the enhancing substrate. However, many of these tests use conventional aqueous colloids which are far from ideal for forensic applications, particularly in field work where handling and mixing solutions is impractical. In addition, there are storage issues with aqueous colloids and so in critical situations materials would probably have to be prepared fresh 
every time they were used. Commercial solid substrates ${ }^{25-29}$ have been developed but their cost is too high for routine use as a screening tool where numerous samples may need to be taken at a single scene. Here we describe highly sensitive solid SERS substrates (Poly-SERS films) ${ }^{30,31}$ which can be used off-theshelf and read using portable hand held Raman spectrometers (in this work the spectrometer dimensions were $c a .133 \times 64 \times$ $38 \mathrm{~mm}$ ). These SERS active films are prepared by simply adding hydroxyethylcellulose polymer to a stirring solution of aggregated metal nanoparticles to which is then poured into a $(100 \mathrm{~mm} \times 100 \mathrm{~mm} \times 50 \mu \mathrm{m}$ ) sheet mould and allowed to completely dry in air. The dry films (see Figure 1) are similar to paper in that they can be cut to size as required for measurements or can be subdivided and then stored ready for use. For example, Figure 1 shows sections of film mounted on aluminium roll backing material which we have found is a convenient way of creating multiple disposable substrates which can easily be stored and transported but can then be cut off and used as required. In normal use, droplets of aqueous analyte are deposited on the films which adsorb the liquid and swell, simultaneously releasing the particle aggregates and bringing them in contact with analyte to generate SERS once a probe laser is directed onto it. These Poly-SERS films provide a convenient and rapid method for either occasional SERS analysis at scenes or routine on-site screening of suspect drugs of abuse which bridges the gap between highly sensitive but time consuming methods such as GC-MS and low specificity and sensitivity methods, such as colorimetric tests.

Initial experiments on seized drugs were carried out under approximately the same conditions as were previously developed for pure pharmaceuticals ${ }^{31}$ and other analytes such as thiophenol ${ }^{30}$, where droplets of aqueous analytes were used. Briefly, $15 \mu \mathrm{L}$ aqueous droplets were deposited onto Ag (CRSC, citrate-reduced silver colloid) Poly-SERS films and allowed to dry before being Raman probed using a Raman microscope. The first test samples were two seized powder samples (A and B) which were similar in colour and texture and which GC-MS and IR analysis (See Supporting Information, Figures. S3 and S4) showed to be predominantly composed of methiopropamine. ${ }^{34}$ Sample A showed some fluorescence

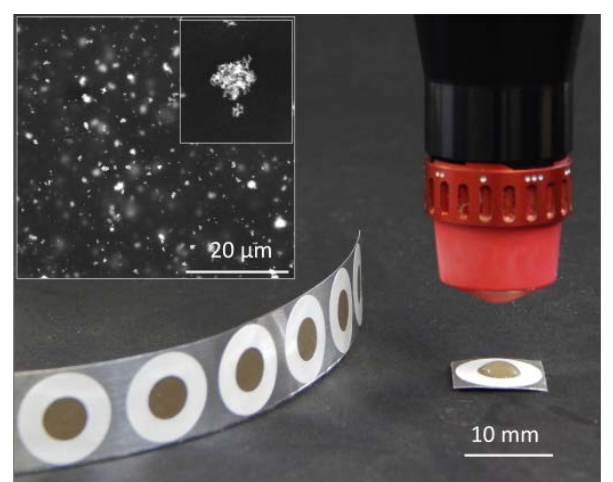

Figure 1: A photograph showing disks of Poly-SERS film mounted on aluminium roll backing material and a single disk which has been swollen with analyte and is being read by a compact Raman spectrometer. Inset shows a 5,000× SEM image of $\mathrm{Ag}$ nanoparticle clusters isolated within a Poly-SERS film, along with a higher magnification image of a single cluster approximately $700 \mathrm{~nm}$ in diameter.

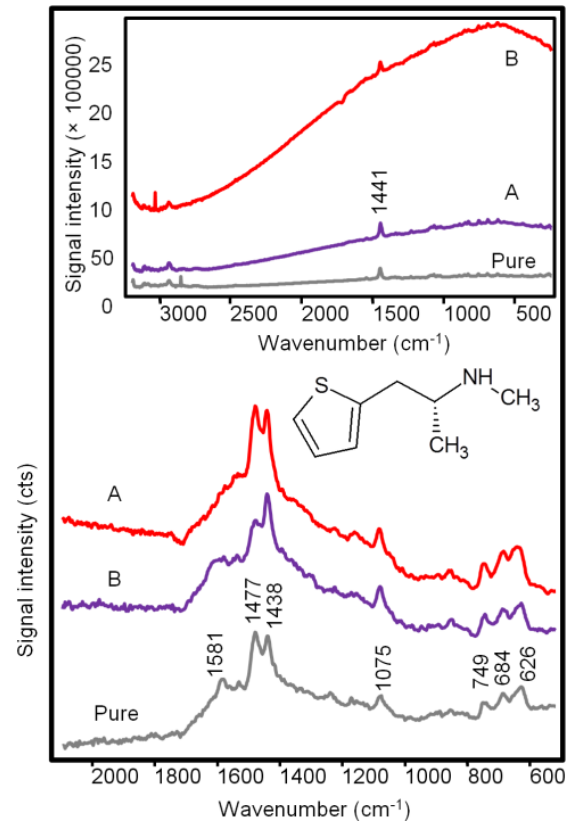

Figure 2: SERS spectra of seized samples $A$ and $B(15 \mu \mathrm{L}$ aqueous droplets on Ag (CRSC) Poly-SERS films, $785 \mathrm{~nm}$ excitation, $30 \mathrm{~s}$ accumulation time) along with that of pure methiopropamine. The spectra are on the same vertical axis, apart from being offset for clarity. Insets show the molecular structure of methiopropamine and the Raman spectra of methiopropamine along with sample powders $A$ and $B$ on the same vertical axis, also obtained with $785 \mathrm{~nm}$ excitation.

while sample B had a much higher level of fluorescence which obscured all but the very strongest bands in the spectra (pure methiopropmmine shows very little fluorescence), see Figure 2. However, when the SERS spectra of aqueous samples of $A$ and $B$ were recorded using a Raman microscope and Ag (CRSC) PolySERS films, characteristic SERS spectra were obtained from both samples (Figure 2) which were very similar to those of pure methiopropamine. The slightly higher relative band intensity at $1438 \mathrm{~cm}^{-1}$ is presumably due to an impurity in the sample which is also enhanced but it is not large enough to interfere with the identification. This example illustrates the potential of the PolySERS films for detection of even fluorescent NPS but it did use laboratory-based instrumentation and was confined to a single target compound. To demonstrate that the signals given by the films are large enough to be detected in a field system, we have recorded the spectra of a series of cathinones using a handheld Raman spectrometer, as shown in Figure 3. These spectra show that the sensitivity of the system is still more than sufficient to record high $\mathrm{S} / \mathrm{N}$ spectra using acceptable accumulation times, even for samples where the total drug content was ca. $100 \mu \mathrm{g}$. Moreover, the resolution, although poorer than laboratory Raman instruments $\left(12-15 \mathrm{~cm}^{-1}\right)$, is still sufficient to allow the samples shown to be discriminated. We have now tested a set of 7 cathinones and found that they all give acceptable SERS spectra with Ag colloids, so the approach 
should be quite general for at least this class of drug compounds.

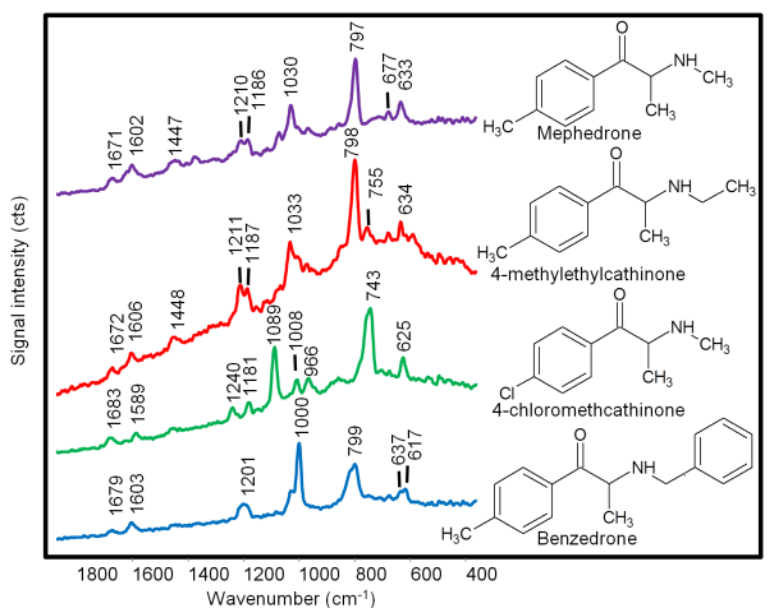

Figure 3: SERS spectra of mephedrone $(130 \mu \mathrm{g}), 4-\mathrm{MEC}(64 \mu \mathrm{g})$, CMC $(120 \mu \mathrm{g})$ and benzedrone $(87 \mu \mathrm{g})$, obtained with preswollen Ag (CRSC) Poly-SERS films and collected using a handheld Raman spectrometer. The spectra are on the same vertical axis, apart from being offset for clarity. Insets show the molecular structures of the cathinones.

Finally, we note that in order to reduce the measurement time for these samples the films were pre-swelled with water before application of the analyte. Under these conditions, the analyte is able to diffuse into the films immediately, which decreases sampling time. An additional modification which can decrease sampling time is to use methanol rather than water as the solvent, which increases the rate of evaporation and this approach was used for the spectra shown in Figure 3. Using methanol makes no detectable difference to the spectra obtained but does mean that methanol of suitable purity needs to be available when the measurement is made. This is not a problem for laboratory analysis but adds an additional requirement that may be more problematic for field use, which is why we have tested both water and methanol.

For bulk samples the primary benefit of using SERS, as opposed to normal Raman measurements, is fluorescence quenching rather than increased sensitivity. However, the ability to detect the presence of small quantities of prohibited substances at scenes also has the potential to aid investigations. For example, in cases where bulk powders are not found but there are items such as weighing scales and used packaging that it might be possible to link with drug-related activities if they were found to carry trace contamination of prohibited substances. The challenge in such circumstances is how to bring the sample into contact with the enhancing substrate. Here we have investigated the possibility of swab sampling since collecting samples on swabs is well established in crime scene examination, for example in phenolphthalein testing for trace blood. Moreover, since evidence/scene contamination is a significant issue, a method such as this, which uses established and proven materials (cotton buds and pure water), will be more readily adopted for forensic applications than novel substrates whose potential for contaminating the scene (e.g. by shedding material onto the evidence sample or the scene generally) has not been properly assessed and tested. The data in Figure 3 demonstrate that if aqueous cathinone samples containing ca. $100 \mu \mathrm{g}$ are directly deposited onto Ag (CRSC) Poly-SERS films, strong signals can be obtained. However, the more relevant question is how much this sensitivity will be compromised when small (typically $\mu$ g) quantities of the sample are picked up by swiping over the area with a water soaked cotton bud and then transferred to the substrate on the swab. Here, trace quantities of methcathinone were deposited from solution onto model substrates (glass microscope slides) and dried so the drug was present as a barely visible solid residue. These model evidence samples were then wiped with a cotton bud wetted with $50 \mu \mathrm{L}$ of water to both dissolve and collect the residue. Immediately after being wiped across the test surface the wet swab was then pressed onto a pre-swelled Ag (HRSC, hydroxylamine reduced silver colloid) Poly-SERS film and then pulled slowly along the surface to transfer some of the solute from the swab to the enhancing film. The SERS spectra were then recorded in the swollen area. Figure 4 shows the SERS spectra recorded in experiments carried out with different quantities of deposited drug. The sensitivity is impressive; a good quality methcathinone spectrum with sufficiently high $\mathrm{S} / \mathrm{N}$ for compound identification was obtained in the experiment where the original mass deposited was $23 \mu \mathrm{g}$. It was possible to detect the most prominent peak $\left(1002 \mathrm{~cm}^{-1}\right)$ of methcathinone in the $2.3 \mu \mathrm{g}$ spectrum but at this level the weaker bands required to make a confident identification were not visible. The calibration plot of the absolute intensity of the strongest SERS band against the mass of methcathinone deposited on the glass slides (shown as an insert to Figure 4) is reasonably linear. This is better than we would have expected since this procedure introduces the possibility of sampling errors in the transfer process as well as those arising from variations in the enhancement factor between films. The sampling error would be expected to be the larger of the two, since the transfer process depends on collecting and the depositing the same proportion of the sample each time which is clearly prone to errors while the Poly-SERS films have previously been shown to have very good enhancement reproducibility ( $3.2 \%$ S.D). ${ }^{30}$ Of course, as for any SERS technique an internal standard could be added to normalise the SERS response of the substrate but here it is not appropriate since this is not the dominant source of error and because the objective here was to develop a field screening test rather than a quantitative analytical method.

Finally, a key aspect of this approach is the shelf life of the enhancing materials, since the objective was to develop an approach which would allow SERS analysis to be available and used as required, even by users who only rarely make use of the technique and who would not be in position to prepare fresh enhancing materials every time the need arose. The Poly-SERS films were designed from the outset to have high stability, since the enhancing nanoparticles are encapsulated in a solid polymer host. This gives exceptional storage times, for example all the SERS spectra shown in Figure 3 were recorded using PolySERS films which had been stored for 1 year at room temperature in a simple glass sample tube. No 


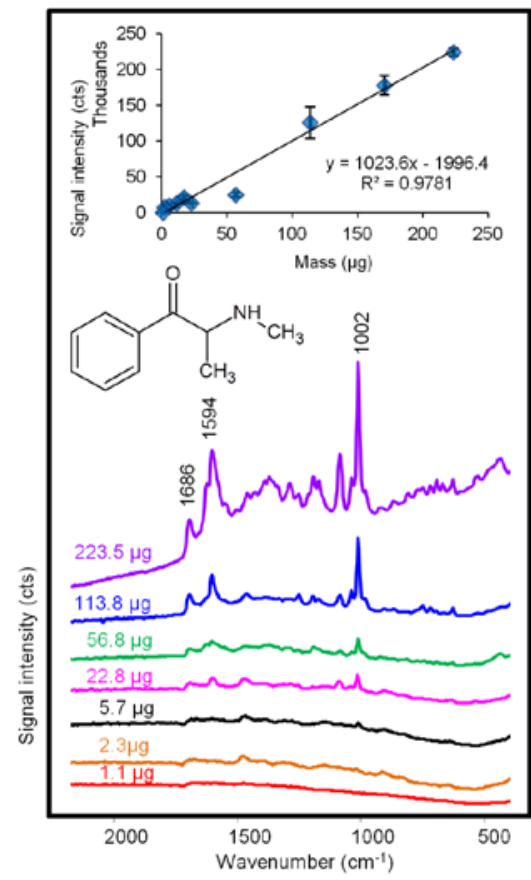

Figure 4: SERS spectra of methcathinone obtained by swabbing substrates which carried the stated mass of drug with a wet cotton bud and then swiping the bud over an Ag (HRSC) PolySERS film. The spectra are on the same vertical axis, apart from being offset for clarity. Insets shows the molecular structure of methcathinone and a calibration plot of average signal intensity of the $1002 \mathrm{~cm}^{-1}$ methcathinone peak versus the mass of methcathinone in the original deposit.

special precautions for excluding oxygen were taken, other than stoppering the container.

In summary, the rapid increase in the number of novel psychoactive substances which are available illicitly is placing an ever increasing burden on the criminal justice system, particularly forensic examiners. The approach of using PolySERS films to identify both fluorescent bulk drugs and to detect trace drugs using a simple swabbing method is a simple and cost-effective way to both screen seized samples without the need for time-consuming and expensive laboratory-based measurements as well as providing new investigative opportunities by allowing objects contained by drugs to be identified at scenes.

Support for this work by the EPRSC (EP/E028543) is acknowledged.

\section{References}

1 F. Smith. Handbook of Forensic Drug Analysis. $1^{\text {st }}$ ed. Academic Press, Alabama, 2004.

2 K. E. Toole, S. Fu, R. G. Shimmon and N. Kraymen, Microgram Journal, 2012, 9, 27-32.

3 S. P. Stewart, S. E.J. Bell, N. C. Fletcher, S. Bouazzaoui, Y. C. Ho, S. J. Speers and K. L. Peters, Anal. Chim. Act., 2012, 711, 1-6.

4 Raman Analysis and Identification of Narcotics and Substances of Abuse Using the RamanStation 400F Online, http://www.perkinelmer.co.uk/CMSResources/Images/4474261AP P_RamanStation400FSubstancesOfAbuse.pdf, (accessed 3/8/2015).
5 M. J. West and M. J. Went, Drug Test Anal., 2011, 3, 532-538. 6 J. M. Chalmers, H. G. M. Edwards and M. D. Hardreaves, Infrared and Raman Spectroscopy in Forensic Science, John Wiley \& Sons, Ltd, Chichester, 2012.

7 S. P. Stewart, S. E. J Bell, W. J. Armstrong, G. Kee and S. J. Speers, J. Raman Spec, 2012, 43, 131-137.

8 J. De Gelder, P. Vandenabeele, F. Govaert and L. Moens, J. Raman Spectrosc., 2005, 36, 1059-1067.

9 S. E. J. Bell, S. P. Stewart and W. J., Armstrong in Raman Spectroscopy for Forensic Analysis of Household and Automotive Paints, in Infrared and Raman Spectroscopy in Forensic Science, eds J. M. Chalmers, H. G. M. Edwards, M. D. Hardreaves, John Wiley \& Sons, Ltd, Chichester, 2012.

10 A. Hakonen, P. O. Andersson, M. S. Schmidt, T. Rindzevicius and M. Kall, Anal. Chim. Acta, 2015, 893, 1-13.

11 K. Faulds, W. E. Smith, D. Graham and R. J. Lacey, Analyst, 2002, 127, 282-286.

12 C. W. Wright, S. D. Harvey and B. W. Wright, Proceedings of the SPIE, 2003, 5048, 107-118.

13 Direct Raman Mapped Imaging of Explosive Materials Online, http://www.horiba.com/fileadmin/uploads/Scientific/Document s/Raman/RA21.pdf (accessed 1/8/2015)

14 Forensic Analysis of Documents Using Raman Spectroscopy Online, https://www.bruker.com/fileadmin/user_upload/8-PDFDocs/OpticalSpectrospcopy/Raman/SENTERRA/AN/AN522_Docume nts_EN.pdf (accessed 1/8/2015).

15 S. E. J. Bell, L. A. Fido, N. M. S. Sirimuthu, S. J. Speers, K. L. Peters and S. H. Cosbey, J. Forensic Sci., 2007, 52, 1063-1067.

16 F. Salahioglu, M. J. Went, and S. Gibson, Anal. Methods, 2013, 5, 5392-5401.

17 P. Gardner, M. F. Bertino, R, Weimer and E. Hazelrigg, Forensic Sci. Int., 2013, 232, 67-72.

18 F. Salahioglu and M. J. Went, Forensic Sci. Int., 2012, 223, 148152.

19 Differentiating bacterial spore from hoax materials by Raman Spectroscopy Online, http://www.rta.biz/images/customerfiles/paperspie20035269anthraxhoax.pdf (accessed August 2015). 20 New York police report suspicious powder incidents Online, http://www.reuters.com/article/2012/05/01/us-usa-occupypowder-idUSBRE84017M20120501 (accessed 1/8/2015).

21 P. L. Stiles, J. A. Dieringer, N.C. Shah and R. P. Van Duyne, Annu. Rev. Anal. Chem., 2008, 1, 601-26.

$22 \mathrm{E}$. Le Ru and P. Etchegoin in Principles of Surface-Enhanced Raman Spectroscopy: and related plasmonic effects, Elsevier, New Zealand, 2008.

23 S. E. J. Bell, S. P. Stewart, Y. C. Ho, B. W. Craythorne and S. J. Speers, J. Raman Specrosc., 2013, 44, 509-517.

24 W. D. Mazzella and P. Buzzini, Forensic Sci. Int. 2005, 152, 241247.

25 Q-SERS Online, http://www.q-sers.com/ (accessed 1/8/2015).

26 Real-Time Analyzers Providing Chemical Information- When and Where You Need It Online, http://www.rta.biz/Content/SERV_Vials.asp (accessed 2/8/2015)

27 SERS Substrates- SERStrate Online, http://www.silmeco.com/products/sers-substrate-serstrate/ (accessed 1/8/2015).

28 Diagnostic anSERS Inc Online, https://www.diagnosticansers.com/ (accessed 1/8/2015).

29 ATOID TM Online, http://atoid.com/ (accessed 2/8/2015).

30 W. W. Y. Lee., V. A. D. Silverson, C. P. McCoy, R. F. Donnelly and S. E. J. Bell, Anal. Chem., 2014, 86, 8106-8113.

31 W. W. Y. Lee, C. P. McCoy, R. F. Donnelly and S. E. J. Bell, Anal. Chim. Acta. 2014. Submitted for publication.

32 P. C. Lee and D. Meisel, J. Phys. Chem., 1982, 86, 3391-3395.

33 N. Leopold, M. Haberkorn, T. Laurell, J. Nilsson, J. R. Baena, J. Frank and B. Lendl, Anal. Chem., 2003, 75, 2166-2171.

34 J. F. Casale and P. A. Hays, Microgram J., 2012, 2, 53-57. 
